\title{
Synthesis, characterization and assessment of anti-quorum sensing activity of copper(II)-ciprofloxacin complex against Pseudomonas aeruginosa PAO1
}

Farzaneh Rafiee ${ }^{1}$, Fakhri Haghi ${ }^{1}$, Rahman Bikas $^{2}$, Azam Heidari ${ }^{3}$, Mina Gholami ${ }^{1}$, Anna Kozakiewicz ${ }^{4}$ and Habib Zeighami ${ }^{*}$

\begin{abstract}
Quorum sensing (QS) inhibition by metal-antibiotic complexes is a promising strategy for the management and control of multidrug resistant Pseudomonas aeruginosa infections. We investigated the anti-quorum sensing activity of sub-minimum inhibitory concentration (sub-MIC) of copper(II) sulfate pentahydrate-ciprofloxacin (Cu-CIP) complex and free ciprofloxacin (free-CIP) against P. aeruginosa PAO1. Copper-CIP complex was synthesized and its characterization was assessed using spectroscopic methods and single crystal X-ray analysis. The effect of sub-MIC (1/4 and $1 / 16 \mathrm{MIC}$ ) concentrations of Cu-CIP and free-CIP on cell growth, biofilm formation, motility, alginate and pyocyanin production, $\mathrm{H}_{2} \mathrm{O}_{2}$ susceptibility and expression of QS circuit genes lasl and las $\mathrm{R}$ in PAO1 was determined. Minimum inhibitory concentration of Cu-CIP complex and free-CIP was determined as $0.125 \mu \mathrm{g} / \mathrm{ml}$. Copper-CIP complex did not show significant effect on the cell growth at concentrations of $1 / 4$ and 1/16 MIC. However, sub-MIC concentrations (1/4 and 1/16 MIC) of Cu-CIP showed the significant reduction in violacein production, motility, biofilm formation, alginate and pyocyanin production and sensitivity to $\mathrm{H}_{2} \mathrm{O}_{2}$ in a concentration dependent manner $(\mathrm{P}<0.001)$. Copper-CIP at the concentration of 1/4 MIC showed the greatest reduction in las/ and las $R$ transcriptional expression (89.5\% and $96.2 \%$ respectively). Considering the biological effects of CU-CIP complex and its inhibitory activity on QS related virulence traits at low concentrations $(0.03$ and $0.007 \mu \mathrm{g} / \mathrm{ml})$, it may be used as an effective approach in the management of infections caused by P. aeruginosa.
\end{abstract}

Keywords: Ciprofloxacin, Metal complex, Pseudomonas aeruginosa, Quorum sensing

\section{Key points}

- Our results indicate the potential of $\mathrm{Cu}$-CIP complex at the concentration of $1 / 4$ MIC to inhibit biofilm formation and QS related genes and virulence traits.

- Considering the beneficial biological effects of this metal complex and its inhibitory effects on biofilm

\footnotetext{
*Correspondence: zeighami@zums.ac.ir

1 Department of Microbiology and Virology, School of Medicine, Zanjan

University of Medical Sciences, Zanjan, Iran

Full list of author information is available at the end of the article
}

formation it may be used as an effective approach in the management of infections caused by $P$. aeruginosa.

\section{Introduction}

Pseudomonas aeruginosa as an important nosocomial pathogen can causes serious infections such as cystic fibrosis, endocarditis, bacteremia, wound, burn and urinary tract infections. The pathogenicity of $P$. aeruginosa is related to different virulence factors like biofilm formation and the production of exotoxins, elastase, alginate 
and sidrophores (Klrissa and Katouli 2016). Resistance to antimicrobial agents and biofilm formation have made it as a serious problem in hospitalized patients (Amini and Namvar 2019). Conventional antimicrobial agents are usually inefficient in the treatment of chronic and persistent infections of $P$. aeruginosa. Development of new therapeutic approaches is necessary to prevent infections caused by drug resistant $P$. aeruginosa (Starkey et al. 2014). Inhibition of quorum sensing (QS) is an effective approach for development of anti-pathogenic agents and control of microbial infections. Quorum sensing, an intercellular communication system, is involved in control of gene expression in response to cell density (Starkey et al. 2014). Pseudomonas aeruginosa has three distinct QS systems including LasI/LasR, RhlI/RhlR, and PQS/MvfR which utilize small diffusible signal molecules of the $\mathrm{N}$-acyl homoserine lactones (AHL) family called autoinducers (AIs). The LasI/R and RhlI/R systems regulate the expression of virulence factors like exotoxin A, LasA protease, LasB elastase, Apr alkaline protease, rhamnolipids, pyocyanin and hydrogen cyanide through signal molecules (Curutiu et al. 2018; Hentzer et al. 2003; Lee and Zhang 2015). Therefore, inhibitors of quorum sensing can be used to attenuate the virulence and pathogenesis and may have a role in control and treatment of acute and persistent infections (Azam et al. 2012; Sadeek et al. 2015). Previous studies showed that the subinhibitory concentrations (sub-MIC) of antibiotics may affect virulence factors like cell surface hydrophobicity, attachment and biofilm formation, motility and sensitivity to oxidative stress. Ciprofloxacin is a broad spectrum antimicrobial agent that has been extensively used for the treatment of several bacterial infections caused by Gram negative and Gram positive strains (Sabale et al. 2012; Uivarosi 2013). Subinhibitory concentrations of ciprofloxacin significantly decreased the virulence factors like motility, biofilm formation, and production of protease, elastase, siderophore, alginate, and rhamnolipid in P. aeruginosa (Khan et al. 2017; Gupta et al. 2016). According to previous studies, the metal-antibiotic complexes possess more biological and antimicrobial activity than free ligands (Sadeek et al. 2015; Sabale et al. 2012). Metal complexes are promising agents for improvement of antimicrobial activity. This property may be explained by chelation theory and overtone concept. According to this theory, the overlapping of the ligand orbital and the partial sharing of the donor groups with positive charge of the metal ion lead to reduction of the metal ion polarity. Furthermore, it enhances delocalization of pielectrons over the whole chelate ring and increases the lipophilicity and penetration of the metal complex into the membrane lipids and blokes the binding sites of metal dependent proteins of the microorganism (Sadeek et al.
2015; Sabale et al. 2012; Uivarosi 2013; Khan et al. 2017). Previous studies have been performed on the antibacterial activities of some metal-ciprofloxacin complexes but the effect of these compounds on P. aeruginosa QS system has not been demonstrated. So, this study aimed to investigated the anti-quorum sensing activity of subMIC concentrations of copper(II) sulfate pentahydrate $\left(\mathrm{CuSO}_{4} \cdot 5 \mathrm{H}_{2} \mathrm{O}\right)$-ciprofloxacin complex $(\mathrm{Cu}-\mathrm{CIP})$ and free ciprofloxacin (free-CIP) against $P$. aeruginosa PAO1.

\section{Materials and methods}

\section{Materials and instrumentation}

Copper(II) sulfate pentahydrate $\left(\mathrm{CuSO}_{4} \cdot 5 \mathrm{H}_{2} \mathrm{O}\right)$ and ciprofloxacin were purchased from Sigma-Aldrich (Buchs, Switzerland) and solvents were bought from Merck (Germany). The elemental analyses (carbon, hydrogen and nitrogen) of the complex were obtained from a Carlo ERBA Model EA 1108 analyzer. The content of copper in the complex was determined by atomic absorption analysis on a Varian Spectra AA-220 equipment. Fourier transform infrared (FT-IR) spectroscopy was performed using a FT-IR Spectrometer Bruker Tensor 27 as $\mathrm{KBr}$ disks. Fresh stock solutions of $\mathrm{Cu}-\mathrm{CIP}$ and free-CIP were prepared in distilled water at the concentration of $1 \mathrm{mg} / \mathrm{ml}$. N-Acyl-homoserine lactone (C6-HSL) (SigmaAldrich) was used at $20 \mu \mathrm{M}$.

\section{Synthesis of $\mathrm{Cu}(\mathrm{II})$-ciprofloxacin complex}

The $\mathrm{Cu}$-CIP complex was synthesized using the reaction of ciprofloxacin $(2.0 \mathrm{mmol}, 0.663 \mathrm{~g})$ and $\mathrm{CuSO}_{4} \cdot 5 \mathrm{H}_{2} \mathrm{O}$ $(2.0 \mathrm{mmol}, 0.499 \mathrm{~g})$ in ethanol $(20 \mathrm{ml})$ and the crystals were directly obtained by thermal gradient method. Briefly, ciprofloxacin and $\mathrm{CuSO}_{4} \cdot 5 \mathrm{H}_{2} \mathrm{O}$ were added to a branched tube and the tube was filled with ethanol. Then, the arm was immersed in an oil bath at $60{ }^{\circ} \mathrm{C}$. After 3 days, cubic green crystals of $\mathrm{Cu}$-CIP were formed which filtered off, washed with cold ethanol and dried at air. Yield: $87 \%$ (1.06 g). Anal. Calc. for $\mathrm{C}_{19} \mathrm{H}_{32} \mathrm{CuFN}_{3} \mathrm{O}_{12} \mathrm{~S}$ $(\mathrm{MW}=609.08 \mathrm{~g} / \mathrm{mol}): \mathrm{C}, 37.47 ; \mathrm{H}, 5.30 ; \mathrm{N}, 6.90 ; \mathrm{Cu}$, $10.43 \%$. Found: C, 37.50; H, 5.28; N, 6.86; Cu, $10.46 \%$. FT-IR (KBr, cm ${ }^{-1}$ ): 3515 (br, m); 3507 (br, m); 3246 (br, m); 3032 (br, m); 2991 (br, w); 2860 (br, w); 2757 (br, w); $2536(\mathrm{w}) ; 1632$ (s); 1629 (s); $1580(\mathrm{~s}) ; 1553(\mathrm{~m}) ; 1525(\mathrm{~m})$; 1495 (m); 1455 (m); 1420 (m); 1381(m); 1358 (m); 1340 (m); 1307 (m); 1295 (m); 1269(m); 1254 (m); 1197 (m); 1183 (m); 1171 (m); 1150 (m); $1134(\mathrm{~m}) ; 1131$ (m); 1119 (m); 1103 (m); 1100 (m); 1057 (m); $1036(\mathrm{~m}) ; 1022(\mathrm{~m}) ;$ $973(\mathrm{w}) ; 950(\mathrm{~m}) ; 926(\mathrm{w}) ; 856(\mathrm{w}) ; 815(\mathrm{w}) ; 757(\mathrm{w}) ; 709$ (w); $629(\mathrm{w}) ; 617(\mathrm{w}) ; 539(\mathrm{w}) ; 508(\mathrm{w}) ; 498(\mathrm{~m}) ; 463(\mathrm{~m})$. The $\mathrm{Cu}-\mathrm{CIP}$ complex was obtained as quite pure single crystals and the X-ray structure was determined. 


\section{Single crystal X-ray analysis}

Crystals of the $\mathrm{Cu}$-CIP complex suitable for the X-ray diffraction experiment were obtained from the ethanol. The diffraction data were collected at room temperature using Oxford Sapphire CCD diffractometer, MoKa radiation $\lambda=0.71073 \AA$, by $\omega-2 \theta$ method. The $\mathrm{Cu}$-CIP structure was solved by direct methods and refined with the full-matrix least-squares procedure on $F^{2}$ (SHELX2014 program packages (Sheldrick 2015). The analytical absorption correction was applied for the studied crystal, based on the crystal shape (Software 2015). All heavy atoms were refined with anisotropic displacement parameters. Positions of $\mathrm{H}$ atoms have been found from the electron density maps and hydrogen atoms were constrained in the refinement with the appropriate riding model as implemented in SHELX during refinement. The results of the data collection and refinement are summarized in Table 1. The structure $\mathrm{Cu}$-CIP has been deposited at the Cambridge Crystallographic Data Centre, the deposition number is 1947979.

\section{Bacterial strains and growth media}

Pseudomonas aeruginosa PAO1 was used for the assay of anti-quorum sensing activity of $\mathrm{Cu}$-CIP complex and free-CIP. Chromobacterium violaceum CV026 was used as reporter strain. The cultures were grown in LuriaBertani (LB) broth/agar (Merck, Germany) aerobically at $37{ }^{\circ} \mathrm{C}$ or $30{ }^{\circ} \mathrm{C}$ for $16-18 \mathrm{~h}$. Bacteria were preserved in Tryptic Soy Broth (TSB, Merck, Germany) containing $10 \%(\mathrm{v} / \mathrm{v})$ glycerol at $-80{ }^{\circ} \mathrm{C}$.

\section{Minimum inhibitory concentration}

Minimum inhibitory concentration (MIC) of $\mathrm{Cu}-\mathrm{CIP}$ and free-CIP was determined using the broth microdilution method (Aziz Zahid et al. 2017). Twofold serial dilutions of compounds $(16,8,4,2,1,0.5,0.25,0.125,0.06,0.03 \mu \mathrm{g} /$ $\mathrm{ml}$ ) were prepared and inoculated with $5 \times 10^{6} \mathrm{CFU} / \mathrm{ml}$ of PAO1 overnight culture. After $24 \mathrm{~h}$ of incubation at $37^{\circ} \mathrm{C}$, MIC was calculated as the lowest concentration of compound that inhibited visible growth of PAO1.

\section{Cell growth analysis}

The growth of both untreated and treated PAO1 was measured by broth microdilution method (Aziz Zahid et al. 2017). Luria-Bertani broth containing the different concentrations of $\mathrm{Cu}-\mathrm{CIP}$ or free-CIP $(0.003$ to $0.5 \mu \mathrm{g} /$ $\mathrm{ml}$ ) was inoculated with PAO1 and incubated at $37^{\circ} \mathrm{C}$ for $16 \mathrm{~h}$. The absorbance was measured at $\mathrm{OD}_{630} \mathrm{~nm}$ and the percentage of cell growth was calculated as follow: $\mathrm{OD}_{630}$ (treated PAO1)/OD 630 (untreated PAO1) $\times 100$.
Table 1 Crystallographic data and refinement details for Cu-CIP

\begin{tabular}{|c|c|}
\hline Compound & $\mathrm{Cu}-\mathrm{CIP}$ \\
\hline Formula & $\mathrm{C}_{17} \mathrm{H}_{32} \mathrm{CuFN}_{3} \mathrm{O}_{12} \mathrm{~S}$ \\
\hline$M_{\mathrm{r}} /(\mathrm{g} / \mathrm{mol})$ & 609.08 \\
\hline Crystal shape, color & Cubic, green \\
\hline Crystal size $/ \mathrm{mm}^{3}$ & $0.30 \times 0.24 \times 0.13$ \\
\hline$\lambda / \AA$ & $0.71073(\mathrm{Mo} \mathrm{Ka})$ \\
\hline Crystal system & Monoclinic \\
\hline Space group & $P 2, / C$ \\
\hline$a / \AA$ & $15.9488(12)$ \\
\hline$b / \AA$ & $11.0141(9)$ \\
\hline$c / \AA$ & $14.6494(12)$ \\
\hline$\beta /^{\circ}$ & $106.958(9)$ \\
\hline$V / \AA^{3}$ & $2461.4(4)$ \\
\hline$Z$ & 4 \\
\hline$D_{\text {calc }} /\left(\mathrm{g} / \mathrm{cm}^{3}\right)$ & 1.644 \\
\hline$\mu / \mathrm{mm}^{-1}$ & 1.05 \\
\hline$F(000)$ & 1268 \\
\hline$\theta$ range $/^{\circ}$ & $2.3-28.6$ \\
\hline$h, k, l$ & $\begin{array}{l}-20 \rightarrow 20 \\
-14 \rightarrow 14 \\
-19 \rightarrow 18\end{array}$ \\
\hline Measured reflections & 16,651 \\
\hline Independent reflections & 5682 \\
\hline Reflections with $/>2 \sigma(I)$ & 4365 \\
\hline$R_{\text {int }}$ & 0.038 \\
\hline$R\left[F^{2}>2 \sigma\left(F^{2}\right)\right]$ & 0.041 \\
\hline$w R\left(F^{2}\right)$ & 0.126 \\
\hline$S$ & 1.06 \\
\hline Abs. correction & Analytical \\
\hline Parameters & 334 \\
\hline Restraints & 0 \\
\hline$\Delta \rho_{\max } / \Delta \rho_{\min }$ & $0.74-0.65$ \\
\hline
\end{tabular}

\section{Biosensor bioassay}

Anti-quorum sensing activity of $\mathrm{Cu}$-CIP and free-CIP was assessed by $C$. violaceum CV026 strain as described previously (Heidari et al. 2017). Fifty microliters of compounds at the concentrations of $1 / 4$ and $1 / 16 \mathrm{MIC}$ were loaded onto wells of $5 \mathrm{~mm}$ on the surface of LB agar inoculated with C. violaceum CV026 and supplemented with $20 \mu \mathrm{M}$ of C6-HSL. Quorum sensing inhibition was determined after $24 \mathrm{~h}$ of incubation at $30{ }^{\circ} \mathrm{C}$ by the presence of a zone of pigmentless but viable cells around the well. Dimethyl sulfoxide (DMSO) was used as a control.

\section{Effects on biofilm formation}

The microtiter plate assay was carried out to determine the effect of $\mathrm{Cu}$-CIP and free-CIP on the biofilm 
formation of PAO1 (Roudashti et al. 2017). Treated (concentration of $1 / 4$ and $1 / 16 \mathrm{MIC}$ of $\mathrm{Cu}-\mathrm{CIP}$ or freeCIP) and untreated cultures of PAO1 in LB broth were incubated overnight at $37{ }^{\circ} \mathrm{C}$. Free cells were removed and biofilms were washed three times with sterile PBS and fixed with $99 \%(\mathrm{v} / \mathrm{v})$ methanol. The adhered cells were stained with $0.2 \%(\mathrm{w} / \mathrm{v})$ crystal violet (HiMedia, India). The additional crystal violet was removed by washing with distilled water. Finally, crystal violet was solubilized using 33\% (v/v) glacial acetic acid for $20 \mathrm{~min}$ and the absorbance was measured at $\mathrm{OD}_{590} \mathrm{~nm}$. The mean of three measurements was reported. The percent inhibition of biofilm formation was calculated as follow: $\left(1-\mathrm{OD}_{590}\right.$ of treated PAO1/OD 590 of untreated $\mathrm{PAO} 1) \times 100$.

\section{Motility assays}

Treated (concentrations of $1 / 4$ and $1 / 16 \mathrm{MIC}$ of $\mathrm{Cu}-$ CIP or free-CIP) and untreated agar plates were used to assess the swarming and twitching motilities (Bahari et al. 2017).

Swarming Nutrient agar (0.5\% Bacto agar) supplemented with $5 \%$ glucose with and without sub-MIC concentrations (1/4 and 1/16 MIC) of compounds was prepared and inoculated with $2 \mu \mathrm{l}$ of PAO1 culture and incubated at $37^{\circ} \mathrm{C}$ for $16 \mathrm{~h}$.

Twitching Treated and untreated LB agar (1\%) plates were prepared and PAO1 cultures were stabbed with a sterile toothpick through the agar layer to the bottom of plate. After $48 \mathrm{~h}$ of incubation at $37^{\circ} \mathrm{C}$, the agar layer was removed and cells attached to plate were stained with crystal violet $(0.1 \%, \mathrm{w} / \mathrm{v})$. Then, the stained zone diameter was measured.

\section{Effects on production of alginate}

The effect of $\mathrm{Cu}$-CIP and free-CIP on the alginate production of PAO1 was assayed according to previous study (Hoffmann et al. 2007). Briefly, $5 \mathrm{ml}$ of LB broth with and without sub-MIC concentrations (1/4 and 1/16 MIC) of compounds were inoculated with $500 \mu \mathrm{l}$ of PAO1 suspension $\left(1 \times 10^{8} \mathrm{CFU} / \mathrm{ml}\right)$ and incubated at $37^{\circ} \mathrm{C}$. After $24 \mathrm{~h}$ of incubation, $1 \mathrm{ml}$ of culture was centrifuged at $12,000 \mathrm{rpm}$ for $30 \mathrm{~min}$ and the supernatant was maintained at $80^{\circ} \mathrm{C}$ for $30 \mathrm{~min}$. The supernatant was then centrifuged at 12,000 rpm for $30 \mathrm{~min}$ and precipitated with ice-chilled ethanol $99 \%(\mathrm{v} / \mathrm{v})$ at $4{ }^{\circ} \mathrm{C}$ for $2 \mathrm{~h}$ and mixed with $1 \mathrm{ml}$ of sterile saline (0.9\%). Finally, $1 \mathrm{ml}$ of borate sulfuric acid reagent $\left(100 \mathrm{mM} \mathrm{H}_{3} \mathrm{BO}_{3}\right.$ in concentrated $\mathrm{H}_{2} \mathrm{SO}_{4}$ ) and $34 \mu \mathrm{l}$ of carbazole reagent (0.1\% in ethanol) were added to $118 \mu \mathrm{l}$ of sample on ice. This mixture was heated to $55^{\circ} \mathrm{C}$ for $30 \mathrm{~min}$ and the absorbance was measured at $\mathrm{OD}_{530} \mathrm{~nm}$.

\section{Effects on pyocyanin production}

Production of pyocyanin was assessed in a quantitative chemical assay (Hoffmann et al. 2007). Briefly, $10 \mathrm{ml}$ of treated (concentrations of $1 / 4$ and $1 / 16 \mathrm{MIC}$ of $\mathrm{Cu}-\mathrm{CIP}$ or free-CIP) and untreated LB broth were inoculated with $500 \mu \mathrm{l}$ of PAO1 suspension $\left(1 \times 10^{8} \mathrm{CFU} / \mathrm{ml}\right)$ and incubated at $37^{\circ} \mathrm{C}$ for $24 \mathrm{~h}$. Five $\mathrm{ml}$ of cell free supernatant was mixed with $3 \mathrm{ml}$ of chloroform. The phase extracted with chloroform was transferred to another test tube and $1 \mathrm{ml}$ of $\mathrm{HCl}(0.2 \mathrm{M}$ in distilled water) was added. After centrifugation at $12,000 \mathrm{rpm}$ for $10 \mathrm{~min}$, the absorbance of red phase was measured at $\mathrm{OD}_{520} \mathrm{~nm}$. The pyocyanin concentration was determined as $\mu \mathrm{g} /$ $\mathrm{ml}=\left(\mathrm{OD}_{520} \times 17.072\right)$.

\section{Effects on hydrogen peroxide susceptibility}

Hydrogen peroxide susceptibility of untreated and treated PAO1 cultures was determined according to previous studies (He et al. 2014; Driscoll et al. 2007). Briefly, $2 \mathrm{ml}$ of treated (concentrations of $1 / 4$ and 1/16 MIC of $\mathrm{Cu}-\mathrm{CIP}$ or free-CIP) and untreated LB broth were inoculated with $100 \mu \mathrm{l}$ of PAO1 suspension $\left(1 \times 10^{8} \mathrm{CFU} /\right.$ $\mathrm{ml}$ ) and incubated at $37^{\circ} \mathrm{C}$ for $24 \mathrm{~h}$. After centrifugation at $5000 \mathrm{rpm}$ for $10 \mathrm{~min}, 100 \mu \mathrm{l}$ of the supernatant were poured onto LB agar plates and a filter paper saturated with $\mathrm{H}_{2} \mathrm{O}_{2}(10 \%, \mathrm{v} / \mathrm{v})$ was placed in the center of plates. After $24 \mathrm{~h}$ of incubation at $37{ }^{\circ} \mathrm{C}$, the inhibition zone diameter was measured and reported in $\mathrm{mm}$.

\section{Extraction of RNA and CDNA synthesis}

RNA was extracted at the middle of the exponential growth phase of treated and untreated PAO1 cultures by EZ-10 Spin Column Total RNA Miniprep Super Kit (Bio Basic, Canada) with on-column DNaseI digestion (Bio Basic, Canada) according to the kit handbook. The purity and concentration of extracted RNA samples were determined by NanoDrop Spectrophotometer (ND-1000, Nano-Drop Technologies, Wilmington, DE). Complementary DNA (cDNA) was then synthesized using PrimeScript ${ }^{\mathrm{TM}} \mathrm{RT}$ reagent Kit (Takara, Japan) in a total volume of $10 \mu \mathrm{l}$ containing $0.5 \mu \mathrm{l}$ of PrimeScript RT Enzyme Mix I, $2 \mu \mathrm{l}$ of $5 \times$ PrimeScript Buffer, $0.5 \mu \mathrm{l}$ of Random 6 mers $(100 \mu \mathrm{M}), 500 \mathrm{ng}$ of RNA and RNase free $\mathrm{dH}_{2} \mathrm{O}$. The reactions were incubated at $37^{\circ} \mathrm{C}$ for $30 \mathrm{~min}$, $85^{\circ} \mathrm{C}$ for $5 \mathrm{~s}$ and $4{ }^{\circ} \mathrm{C}$ for $10 \mathrm{~min}$.

\section{Real time PCR}

The effect of sub-MIC concentrations (1/4 and $1 / 16$ $\mathrm{MIC}$ ) of $\mathrm{Cu}-\mathrm{CIP}$ and free-CIP on expression of lasI and lasR genes of PAO1 was assessed as described previously (Bahari et al. 2017; Roudashti et al. 2017). Real time PCR reaction mixture was composed of $10 \mu \mathrm{l}$ of TB Green 
Premix Ex Taq (Takara, Japan), $0.4 \mu \mathrm{l}$ of ROX Reference Dye $(50 \times), 0.4 \mu \mathrm{l}$ of each primer $(10 \mu \mathrm{M}), 1 \mu \mathrm{l}$ of cDNA (100 ng) and $7.8 \mu \mathrm{l}$ of sterile purified water to complete the volume. Assays were carried out with an Applied Biosystems StepOnePlus ${ }^{\mathrm{TM}}$ Real-Time PCR System in triplicate. The expression level of lasI and lasR genes was normalized to the expression of reference gene oprL. Analysis of melting curve showed that the accumulation of TB Green-bound DNA was specific for lasI or lasR genes. The no template control (NTC) and no reverse transcriptase control (no-RT) were included in all experiments. The expression of treated cultures was compared with untreated cultures and the data were analysed by $2^{-}$ $\Delta \Delta \mathrm{Ct}$ method (Cuprys et al. 2018).

\section{Statistical analysis}

All data were analyzed using SPSS version 17.0 software. The statistical analysis of data was carried out using oneway analysis of variance (ANOVA). Differences with $P$ value $<0.05$ were considered significant.

\section{Results}

\section{Synthesis and characterization of Cu-CIP complex}

The reaction of ciprofloxacin with copper(II) sulfate pentahydrate in ethanol gave green crystals by thermal gradient method. In the FT-IR spectrum of the crystals, the peaks at $1629,1580,1254$ and $3032 \mathrm{~cm}^{-1}$ can be attributed to the $\mathrm{C}=\mathrm{N}, \mathrm{C}=\mathrm{C}, \mathrm{C}-\mathrm{O}$, and $\mathrm{C}-\mathrm{H}$ bond vibrations. The peak at $1632 \mathrm{~cm}^{-1}$ is due to the coordinated carboxylate $\left(-\mathrm{CO}_{2}\right)$ group which confirms the coordination of carboxylate group to the copper(II) ion. The band at $1171 \mathrm{~cm}^{-1}$ is due to the $\mathrm{C}-\mathrm{F}$ vibration and the broad bands at about 3500 and $3246 \mathrm{~cm}^{-1}$ are due to the $\mathrm{OH}$ and $\mathrm{NH}$ groups, respectively which are involved in intermolecular hydrogen bond interactions.
The structure of green crystals was characterized using single crystal X-ray analysis. Copper-CIP molecular structure is shown in Fig. 1 and selected bond lengths and angles are presented in Table 2. Diffraction studies indicated that $\mathrm{Cu}-\mathrm{CIP}$ is crystallized in $\mathrm{P} 2{ }_{1} / c$ space group of monoclinic system and is a mononuclear complex of $\mathrm{Cu}(\mathrm{II})$. The complex is cationic and a sulfate anion is located beside it. The coordination environment around $\mathrm{Cu}$ (II) ion is generated by coordination of two oxygen atoms (carboxylate and ketonic groups) from ciprofloxacin, two oxygen atoms from coordinated water molecules and one oxygen atom from coordinated ethanol solvent. The coordination environment can be described as square pyramidal geometry with the $\tau$ value of 0.0945 ( $\tau=$ difference between the two largest angles/60; $\tau=1$ for ideal trigonal-bipyramidal and $\tau=0$ for ideal squarepyramidal). During the formation of $\mathrm{Cu}$-CIP, the hydrogen atom of carboxylic acid functionality is eliminated and the nitrogen atom of piperazine ring is protonated.

Table 2 Selected bond lengths $(\AA)$ and bond angles $\left({ }^{\circ}\right)$ in the crystal structure of $\mathrm{Cu}-\mathrm{CIP}$

\begin{tabular}{llll}
\hline Bond & Length/Å & Bond & Angle/ $^{\circ}$ \\
\hline Cu1-O20 & $1.9121(18)$ & O20-Cu1-O23 & $92.86(8)$ \\
Cu1-O23 & $1.917(2)$ & O20-Cu1-O27 & $164.11(10)$ \\
Cu1-O27 & $1.956(2)$ & O23-Cu1-O27 & $88.95(9)$ \\
Cu1-O28 & $1.969(2)$ & O20-Cu1-O28 & $86.14(8)$ \\
Cu1-O24 & $2.256(3)$ & O23-Cu1-O28 & $169.78(10)$ \\
C8-F1 & $1.354(3)$ & O27-Cu1-O28 & $89.28(9)$ \\
C2-N3 & $1.492(3)$ & O20-Cu1-O24 & $103.45(10)$ \\
N3-C4 & $1.482(3)$ & O23-Cu1-O24 & $97.15(11)$ \\
N13-C17 & $1.343(3)$ & O27-Cu1-O24 & $91.97(10)$ \\
N13-C14 & $1.461(3)$ & O28-Cu1-O24 & $92.97(10)$ \\
C11-N13 & $1.401(3)$ & & \\
\hline
\end{tabular}

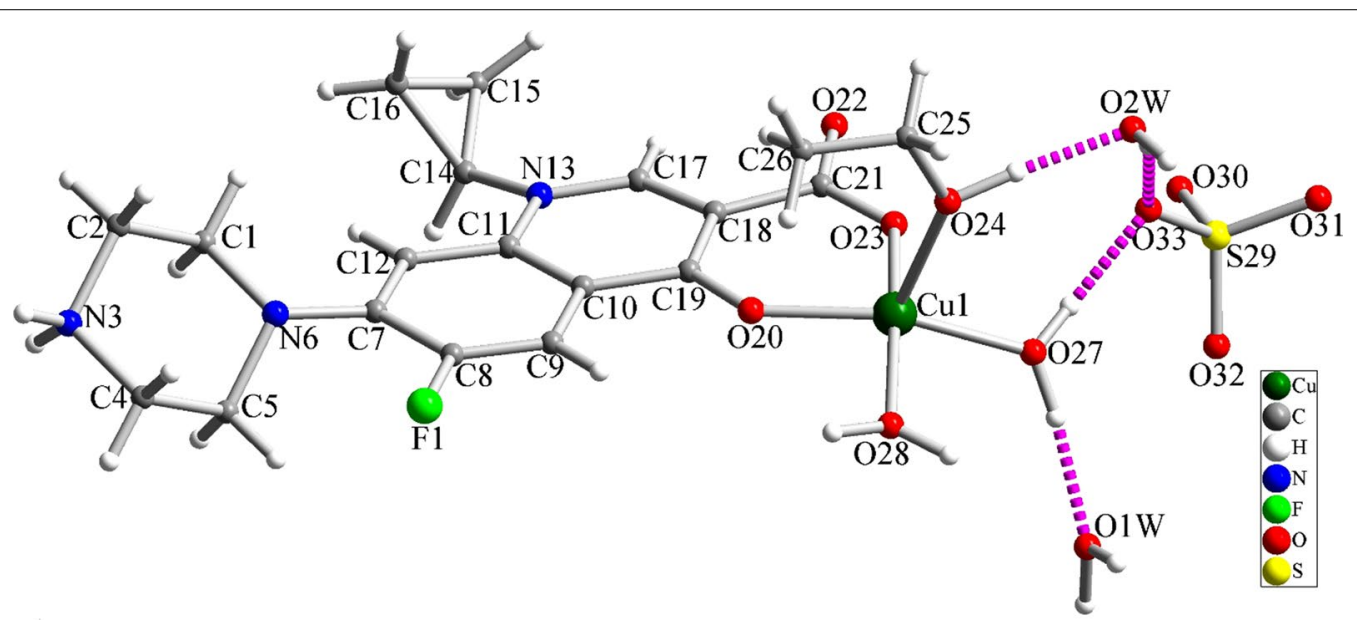

Fig. 1 The molecular structure of Cu-CIP with atom labeling. Pink dashed lines show hydrogen bond interactions 
Therefore, ciprofloxacin acts as a neutral bidentate $\mathrm{O}_{2}$-donor ligand in $\mathrm{Cu}$-CIP. By considering the presence of $\mathrm{Cu}(\mathrm{II})$, the complex molecule is a cationic complex and the +2 positive charge is balanced by -2 sulfate anion. There are three uncoordinated water molecules in the crystal structure of $\mathrm{Cu}$-CIP which are stabilized in the crystal by strong and directed hydrogen bond interactions. The sulfate anion is also stabilized in the crystal structure of $\mathrm{Cu}$-CIP by involving in hydrogen bond interactions. Each oxygen atoms of the $\mathrm{SO}_{4}{ }^{2-}$ anion involves two hydrogen bond interactions which have considerable effect in stabilization of the crystal structure. A part of the hydrogen bond interactions in the crystal structure of $\mathrm{Cu}-\mathrm{CIP}$ is shown in Fig. 2 and the detailed information of hydrogen bond interactions is presented in Table 2. These intermolecular interactions connect the molecules to each other and create 3D polymeric network (see Figs. 1 and 2).

\section{MIC determination}

Copper-CIP and free-CIP MIC against PAO1 was determined as $0.125 \mu \mathrm{g} / \mathrm{ml}$. Sub-inhibitory concentrations of $\mathrm{Cu}-\mathrm{CIP}$ and free-CIP corresponding to $1 / 4$ and $1 / 16 \mathrm{MIC}$ (0.031 and $0.007 \mu \mathrm{g} / \mathrm{ml}$, respectively) were applied to assess QSI activity.

\section{Cell growth analysis}

The effect of different concentrations of $\mathrm{Cu}$-CIP and free-CIP on cell growth of PAO1 is shown in Fig. 3. The concentration of $0.125 \mu \mathrm{g} / \mathrm{ml}$ of $\mathrm{Cu}-\mathrm{CIP}$ or free-CIP $(1 \times \mathrm{MIC})$ significantly decreased the cell growth in comparison with untreated PAO1. However, the cell growth was not significantly reduced at the concentrations of $1 / 4$

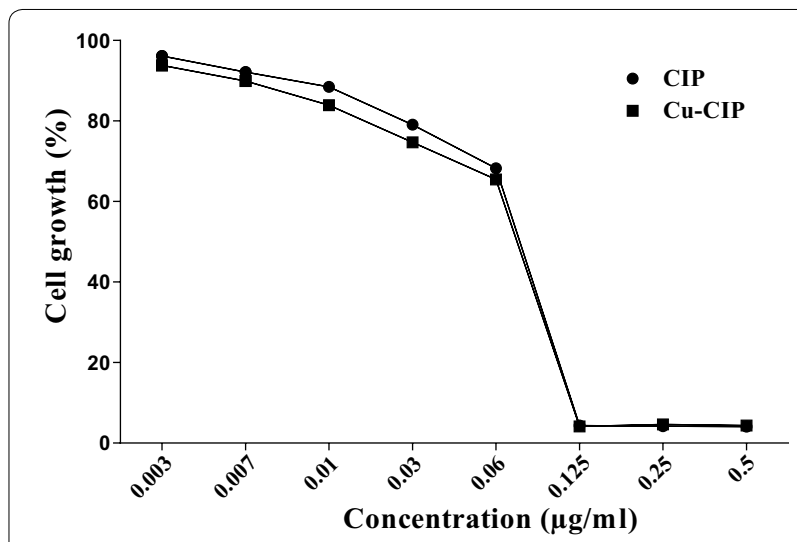

Fig. 3 The effect of concentrations of 0.003 to $0.5 \mu \mathrm{g} / \mathrm{ml}$ of ciprofloxacin (CIP) and copper-ciprofloxacin complex (Cu-CIP) on cell growth of $\mathrm{PAO} 1$

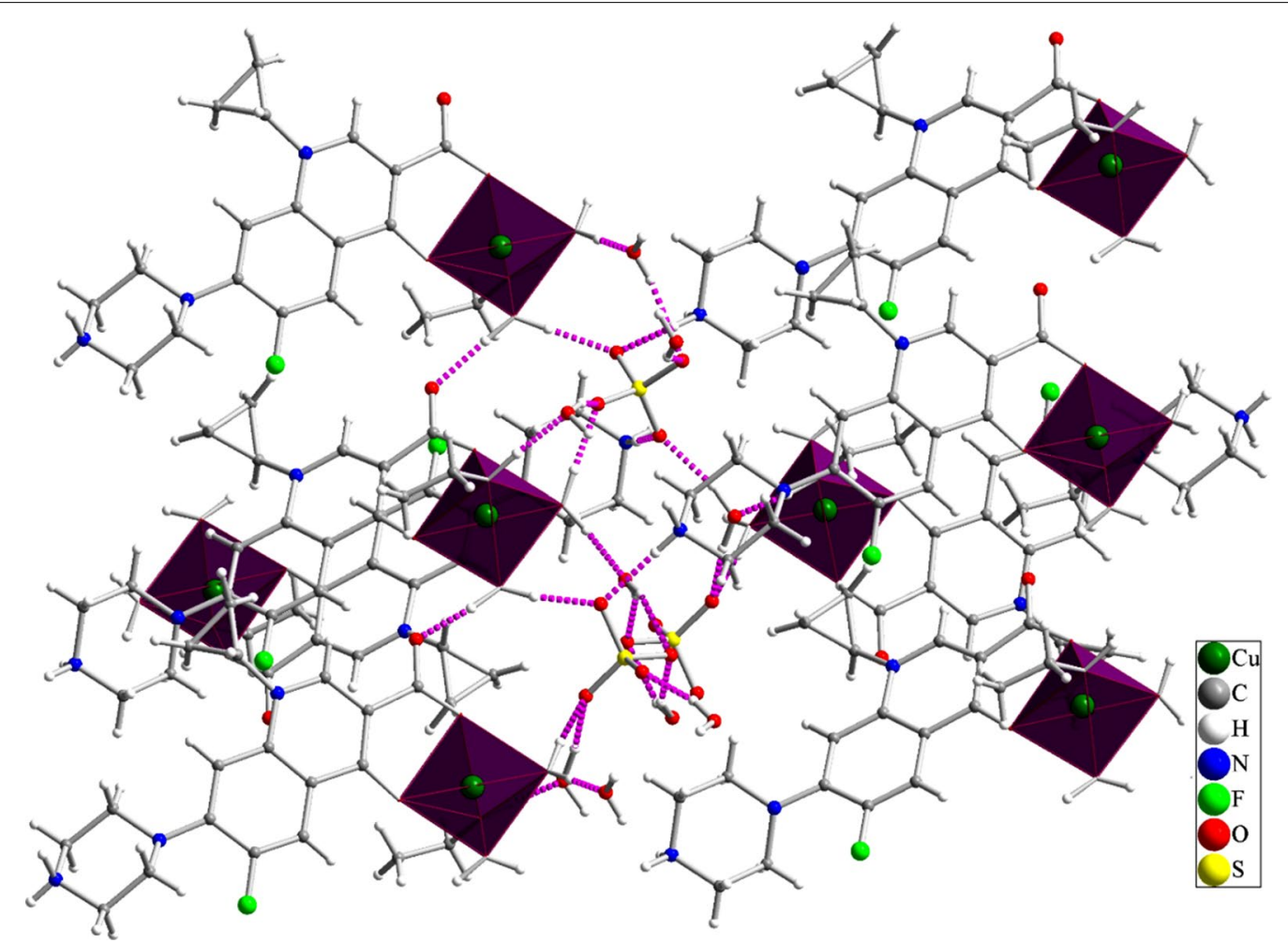

Fig. 2 Intermolecular hydrogen bond interactions (pink dashed lines) in the crystal structure of Cu-CIP 
and 1/16 MIC of compounds compared with untreated control.

\section{Biosensor bioassay}

Copper-CIP and free-CIP showed anti-quorum sensing activity in $C$. violaceum CV026 biosensor bioassay. The concentrations of $1 / 4$ and $1 / 16$ MIC of free-CIP showed the pigmentless zones of 16 and $11 \mathrm{~mm}$, respectively, indicating the violacein inhibition around the wells. Whereas, $\mathrm{Cu}$-CIP showed stronger anti-quorum sensing activity at the concentrations of $1 / 4$ and $1 / 16 \mathrm{MIC}$ with pigmentless zones of 23 and $18 \mathrm{~mm}$, respectively.

\section{Effects on biofilm formation}

The biofilm formation was inhibited in the presence of $\mathrm{Cu}$-CIP or free-CIP between 34 and $84 \%$ (Fig. $4 \mathrm{a}$ ). The inhibitory effect was concentration dependent. Biofilm inhibition was significantly higher at the concentrations of $1 / 4$ and $1 / 16 \mathrm{MIC}$ of $\mathrm{Cu}$-CIP compared with free-CIP $(P<0.001)$. Furthermore, the concentration of $1 / 4$ MIC of $\mathrm{Cu}$-CIP demonstrated the most inhibitory effect on biofilm formation with $84 \%$ reduction $(P<0.001)$.

\section{Effects on motility}

Swarming and twitching motilities were significantly decreased at the concentrations of $1 / 4$ MIC and 1/16 $\mathrm{MIC}$ of $\mathrm{Cu}$-CIP or free-CIP in comparison with untreated PAO1 $(P<0.05)$ (Fig. 4b). There was a $56.5 \%$ decrease in twitching and $51.2 \%$ decrease in swarming motility at the concentration of $1 / 4 \mathrm{MIC}$ of $\mathrm{Cu}$-CIP. The rate of motility reduction was significantly higher in the presence of $\mathrm{Cu}$ CIP compared with free-CIP $(P<0.05)$.

\section{Effects on alginate production}

As shown in Fig. 5a, the concentrations of $1 / 4$ and $1 / 16 \mathrm{MIC}$ of $\mathrm{Cu}$-CIP or free-CIP exhibited $36.5 \%$ to $80.9 \%$ reduction in alginate production compared with untreated PAO1 $(\mathrm{P}<0.05)$. The most inhibitory effect on alginate production was detected at the concentration of $1 / 4 \mathrm{MIC}$ of $\mathrm{Cu}$-CIP with $80.9 \%$ reduction $(P<0.001)$.

\section{Effects on pyocyanin production}

The effect of $\mathrm{Cu}$-CIP and free-CIP on pyocyanin production is shown in Fig. 5b. Pyocyanin production was significantly reduced (ranging from 21 to 50\%) at the concentrations of $1 / 4$ and $1 / 16 \mathrm{MIC}$ of $\mathrm{Cu}$-CIP or freeCIP in comparison with untreated PAO1 $(P<0.05)$. There was no significant difference in pyocyanin reduction between $\mathrm{Cu}$-CIP and free-CIP at the concentrations of $1 / 4$ and $1 / 16$ MIC.

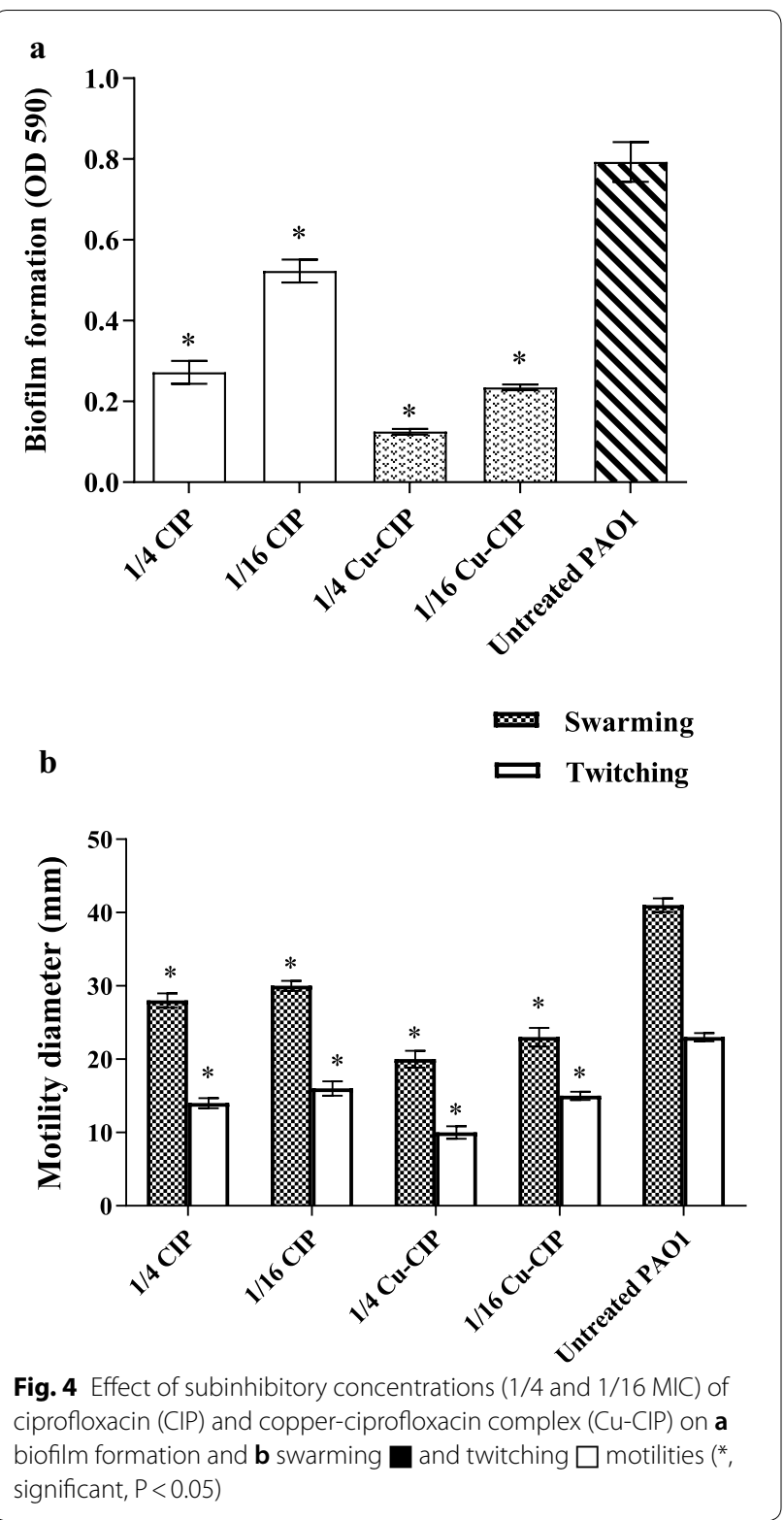

\section{Effects on hydrogen peroxide susceptibility}

The concentrations of $1 / 4$ and $1 / 16 \mathrm{MIC}$ of $\mathrm{Cu}-\mathrm{CIP}$ or free-CIP significantly increased the sensitivity of PAO1 to $\mathrm{H}_{2} \mathrm{O}_{2}$ in comparison with untreated PAO1 (ranged from 1.7- to 2.1-fold) $(P<0.05)$ (Fig. 5c). The concentration of $1 / 4 \mathrm{MIC}$ of $\mathrm{Cu}-\mathrm{CIP}$ showed the most sensitivity to $\mathrm{H}_{2} \mathrm{O}_{2}$ by 2.1 fold $(P<0.05)$.

\section{Expression of lasl and lasR}

Relative expression of lasI and lasR genes was determined from $\mathrm{Ct}$ values and standard curves. The melting curve analysis showed the same profiles without dimer 

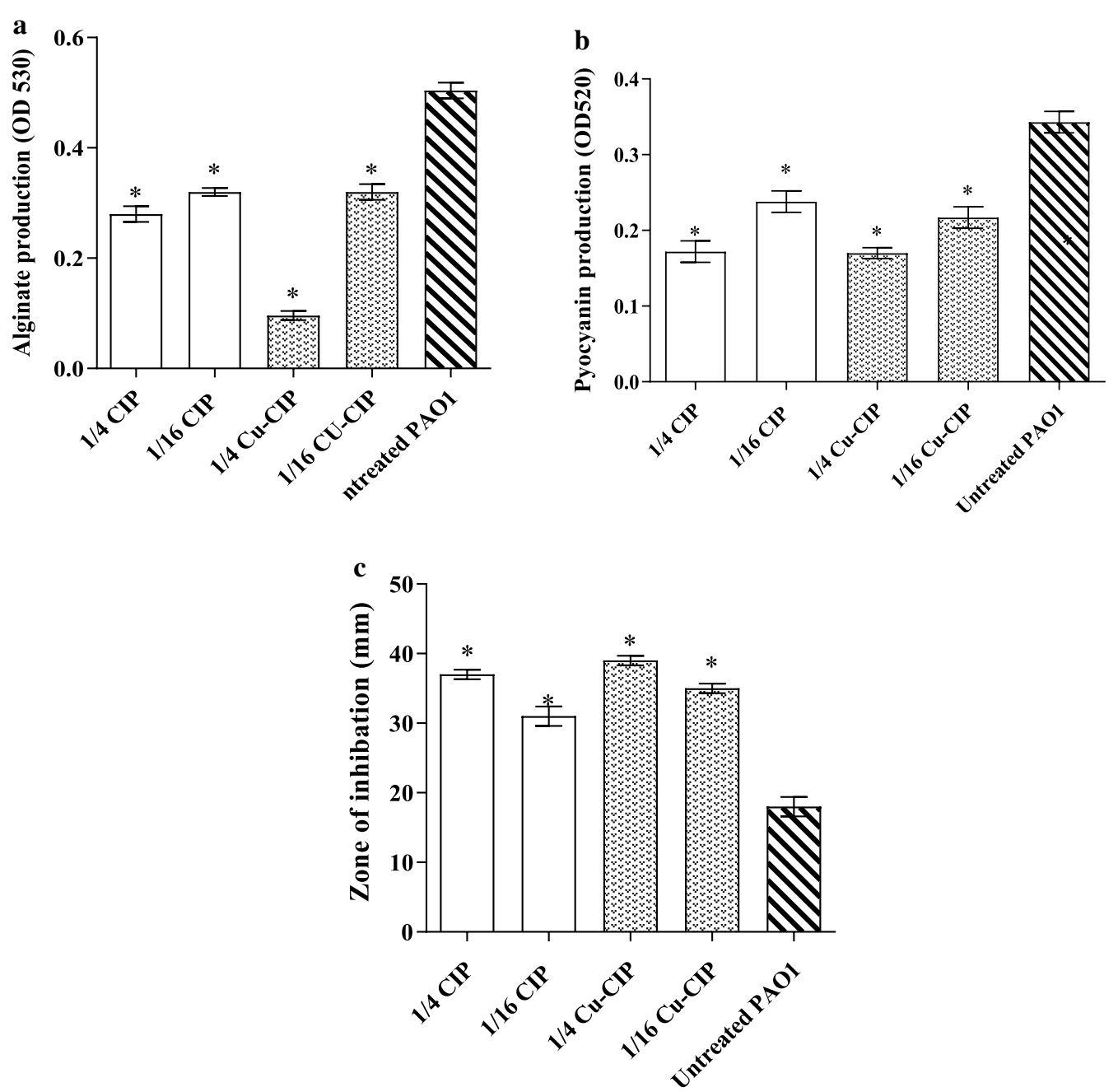

Fig. 5 Effect of subinhibitory concentrations (1/4 and 1/16 MIC) of ciprofloxacin (CIP) and copper-ciprofloxacin complex (Cu-CIP) on a the alginate production, b pyocyanin production and $\mathbf{c} \mathrm{H}_{2} \mathrm{O}_{2}$ susceptibility (*, significant, $\mathrm{P}<0.05$ )

primer formation. The standard curve of oprL and target genes of lasI and lasR showed R2 values 0.99-0.97. Relative expression of treated cultures was compared with untreated cultures and the data were analyzed using $2^{-\Delta \Delta \mathrm{Ct}}$ method. Copper-CIP and free-CIP significantly repressed the expression of lasI and lasR between 18.3 and $96.2 \%$ relative to untreated PAO1 $(P<0.05)$ (Fig. 6). The concentration of $1 / 4 \mathrm{MIC}$ of $\mathrm{Cu}-\mathrm{CIP}$ showed the greatest reduction in lasI and lasR expression $(89.5 \%$ and $96.2 \%$ respectively) $(P<0.001)$. The reduction in lasI and lasR expression was significantly higher in the presence of $\mathrm{Cu}$-CIP compared with free-CIP $(P<0.05)$.

\section{Discussion}

Inhibition of quorum sensing by metal-drug complexes is a promising strategy for control of drug resistant bacterial infections (Driscoll et al. 2007; Sabale et al. 2012;

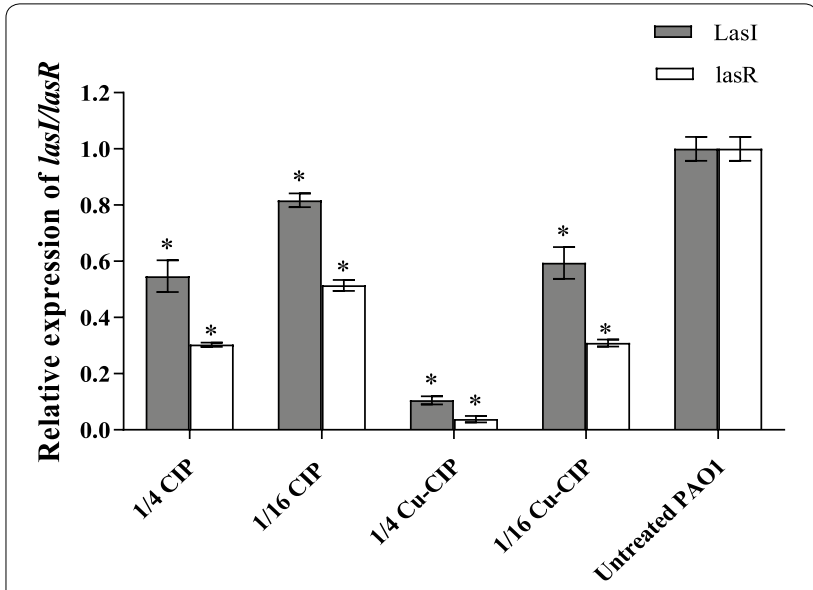

Fig. 6 The subinhibitory concentrations (1/4 and 1/16 MIC) of ciprofloxacin (CIP) and copper-ciprofloxacin complex (Cu-CIP) inhibited QS regulated genes in treated PAO1 ( ${ }^{*}$, significant, $\left.\mathrm{P}<0.05\right)$ 
Uivarosi 2013; Khan et al. 2017). Previous studies have been reported the anti-tumor, anti-fungal, anti-viral, anti-bacterial and special biological activities of metal complexes (Sabale et al. 2012; Khan et al. 2017). It has been found that the metal complexes of quinolones possess more biological and antibacterial activities than free quinolones (Sabale et al. 2012). However, the effect of metal complexes of ciprofloxacin on $P$. aeruginosa $\mathrm{QS}$ system has not been demonstrated. As far as we know, this is the first study to demonstrate anti-quorum sensing activity of sub-MIC concentrations of $\mathrm{Cu}$-CIP complex against $P$. aeruginosa. According to our results, minimum inhibitory concentration of $\mathrm{Cu}$-CIP complex and free-CIP was determined as $0.125 \mu \mathrm{g} / \mathrm{ml}$. Cuprys et al. (2018) also reported similar results on MIC values of $\mathrm{Cu}$-CIP complex and free-CIP against $P$. aeruginosa (Cuprys et al. 2018). Copper-CIP and free-CIP decreased the cell growth of PAO1 at concentrations of $1 \times$ MIC. However, the cell growth was not significantly reduced at concentrations of $1 / 4$ and $1 / 16 \mathrm{MIC}$, proving that their anti-quorum sensing activities were obtained by QS inhibition not through bacterial cell killing. Similar results were reported by El-Mowafy et al. (2014) which showed that sub-MIC concentrations of aspirin significantly decreased the quorum sensing signals of $P$. aeruginosa without reduction in cell growth (El-Mowafy et al. 2014). In the lack of significant effect of $\mathrm{Cu}$-CIP on the cell growth at concentrations of $1 / 4$ and 1/16 MIC, it demonstrated anti-quorum sensing activity in C. violaceum CV026. Free-CIP also showed a concentrationdependent reduction in violacein production. However, $\mathrm{Cu}$-CIP complex showed stronger anti-quorum sensing activity in comparison with free-CIP. Similar to our results, sub-MIC concentrations of compounds such as curcumin, furanone and its derivatives, pyridoxal lactohydrazone, cinnamaldehyde and its derivatives, iberin, ajoene, catachin and some antibiotics significantly inhibited QS signaling (Heidari et al. 2017; Roudashti et al. 2017; Bahari et al. 2017; El-Mowafy et al. 2014; Tang and Zhang 2014; Manner and Fallarero 2018).

Biofilm formation is an important virulence factor involved in the pathogenicity, drug resistance and development of chronic and persistent infections of $P$. aeruginosa (Amini and Namvar 2019; Lee and Zhang 2015). Since quorum sensing system is an important regulating factor in the biofilm formation, its inhibition may promote the eradication of biofilms (Hentzer et al. 2003). The concentration of $1 / 4 \mathrm{MIC}$ of $\mathrm{Cu}-\mathrm{CIP}$ complex demonstrated the most inhibitory effect on biofilm formation with $84 \%$ reduction. Furthermore, biofilm inhibition was significantly higher in the presence of $\mathrm{Cu}$-CIP compared with free-CIP. In study conducted by Tewes et al. (2019), efficacy of ciprofloxacin and its copper complex was determined against $P$. aeruginosa biofilms. According to their reports, there was no difference between free-CIP and $\mathrm{Cu}$-CIP in terms of efficacy against biofilm (Tewes et al. 2019). In accordance with our results, Packiavathy et al. (2012) and Gopu et al. (2015) also reported a significant decrease in biofilm formation of food-borne pathogens treated with $10 \mu \mathrm{g} / \mathrm{ml}$ of methyl eugenol or $40 \mu \mathrm{g} / \mathrm{ml}$ of quercetin (Packiavathy et al. 2012; Gopu et al. 2015). Significant reduction in biofilm formation was also reported at sub-MIC concentrations of curcumin in combination with ciprofloxacin, ceftazidime, azithromycin and gentamicin in our previous studies (Roudashti et al. 2017; Bahari et al. 2017). In study conducted by Bortolotti et al. (2019), a quorum sensing inhibitor conjugated with ciprofloxacin (ET37) showed a decrease in biofilm formation and antibiotic tolerance of clinical strains of $P$. aeruginosa (Bortolotti et al. 2019).

Swarming and twitching motilities in PAO1 treated with $\mathrm{Cu}$-CIP complex or free-CIP was significantly impaired relative to untreated control. However, the rate of motility reduction was significantly higher in the presence of $\mathrm{Cu}$-CIP compared with free-CIP. These findings are consistent with previous reports which demonstrated that curcumin (Bahari et al. 2017; Roudashti et al. 2017), aspirin (El-Mowafy et al. 2014), pyridoxal lactohydrazone (Heidari et al. 2017) and green synthesized nanocomposites (Alavi and Karimi 2018) inhibit swarming and twitching motilities in P. aeruginosa.

In our study, significant reduction in virulence factors was detected at the concentrations of $1 / 4$ and 1/16 MIC of $\mathrm{Cu}$-CIP complex. Copper-CIP complex significantly decreased the alginate (36.5-80.9\%) and pyocyanin (37$50 \%)$ production compared with untreated PAO1. Heidari et al. (2017) reported that pyridoxal lactohydrazone at the concentration of $1 / 4$ MIC decreased the alginate production up to $64 \%$ in PAO1 compared with untreated control (Heidari et al. 2017). Pyocyanin as a secondary metabolite produced by $P$. aeruginosa generates reactive oxygen radicals and therefore kills other microbes and mammalian cell during bacterial infections. According to previous reports, pyocyanin inhibition showed the bactericidal activity and increased the sensitivity to oxygen free radicals (Heidari et al. 2017). In previous studies, sub-MIC concentrations of azithromycin, ceftazidime and ciprofloxacin repressed the QS activity of $P$. aeruginosa via restraining cellular permeability and inhibiting the release of QS signal C12-HSL in the surrounding environment (Bahari et al. 2017; Roudashti et al. 2017; El-Shaer et al. 2016). Similarly, sub-MIC concentrations of trans-cinnamaldehyde and salicylic acid significantly decreased virulence factors and inhibited the expression of lasI/R and rhlI/R systems in PAO1 (Ahmed et al. 2019). We also confirmed that PAO1 was more sensitive 
to $\mathrm{H}_{2} \mathrm{O}_{2}$ at concentration of $1 / 4 \mathrm{MIC}$ of $\mathrm{Cu}$-CIP complex. According to $\mathrm{He}$ et al. (2014) findings, combination of chito-oligosaccharide (COS) with azithromycin showed synergistic effects. Sub-MIC concentration of COS with azithromycin also inhibited the virulence factors and biofilm development in resistant and wild-type strains of $P$. aeruginosa (He et al. 2014).

Our study indicated that $\mathrm{Cu}$-CIP complex or free-CIP significantly inhibited the expression of lasI and lasR relative to untreated PAO1. Copper-CIP showed the greatest reduction in the expression of lasI and lasR at the concentration of 1/4 MIC. Due to the important role of QS in regulation of virulence factors and biofilm formation, we speculated that $\mathrm{Cu}$-CIP mediated inhibition of these factors is obtained by effects on QS.

A new $\mathrm{Cu}$ (II)-CIP complex was synthesized by the reaction of $\mathrm{Cu}(\mathrm{II})$ sulfate pentahydrate and ciprofloxacin in ethanol and the product was characterized using spectroscopic methods and single crystal X-ray analysis. The anti-quorum sensing activity of complex against $P$. aeruginosa was also determined. Our results indicate the potential of $\mathrm{Cu}$-CIP complex at the concentration of $1 / 4$ MIC to inhibit biofilm formation and QS related genes and virulence traits. Considering the beneficial biological effects of this metal complex and its inhibitory effects on biofilm formation and QS related virulence traits at low concentrations $(0.03$ and $0.007 \mu \mathrm{g} / \mathrm{ml})$, it may be used as an effective approach in the management of infections caused by $P$. aeruginosa.

\section{Acknowledgements}

The authors acknowledge to Department of Microbiology, for providing lab facility to carry out this work.

\section{Authors' contributions}

FR and MG involved in the project development, data management. RB and AH participated in project development, data analysis. AK participated in $\mathrm{X}$ ray development, $\mathrm{FH}$ and $\mathrm{HZ}$ involved in the project development, data management and manuscript writing. All authors read and approved the final manuscript.

\section{Funding}

The present study was funded by the Zanjan University of Medical Sciences (A-12-392-30; ZUMS.REC.1397.368) as a MSc thesis in Medical Microbiology.

\section{Availability of data and materials}

It is the responsibility of each author for providing authenticated data and material and data would be made available also.

\section{Ethics approval and consent to participate}

Current research report doesn't contain any data collected from humans or animals and also there was no involvement of human participants and doesn't belongs to any health related outcomes and reports. But registered as ZUMS. REC.1397.368 code.

\section{Consent for publication}

This research article entitled as Synthesis, Characterization and Assessment of Anti-Quorum Sensing Activity of Copper(II)-Ciprofloxacin Complex against Pseudomonas aeruginosa PAO1an original work was carried out by authors, who all are agree to submit this Manuscript to AMB express journal for probable publication. The manuscript has not been previously published, is not currently submitted for review to any other journal, and will not be submitted elsewhere before a decision is made by this journal. I am the author responsible for the submission of this article and I accept the conditions of submission and the Springer Open Copyright and License Agreement.

\section{Competing interests}

The authors declare that they have no competing interests.

\section{Author details}

${ }^{1}$ Department of Microbiology and Virology, School of Medicine, Zanjan University of Medical Sciences, Zanjan, Iran. ${ }^{2}$ Department of Chemistry, Faculty of Science, Imam Khomeini International University, Qazvin 34148-96818, Iran. ${ }^{3}$ School of Medicine, Zanjan University of Medical Sciences, Zanjan, Iran. ${ }^{4}$ Department of Biomedical and Polymer Chemistry, Faculty of Chemistry, Nicolaus Copernicus University in Torun, 87-100 Toruń, Poland.

Received: 7 April 2020 Accepted: 18 April 2020

Published online: 24 April 2020

\section{References}

Ahmed SAKS, Rudden M, Smyth TJ, Dooley JSG, Marchant R, Banat IM (2019) Natural quorum sensing inhibitors effectively downregulate gene expression of Pseudomonas aeruginosa virulence factors. Appl Microbiol Biotechnol 103:3521-3535

Alavi M, Karimi N (2018) Antiplanktonic, antibiofilm, antiswarming motility and antiquorum sensing activities of green synthesized $\mathrm{Ag}-\mathrm{TiO}_{2}, \mathrm{TiO}_{2}-\mathrm{Ag}$, $\mathrm{Ag}-\mathrm{Cu}$ and $\mathrm{Cu}-\mathrm{Ag}$ nanocomposites against multi-drug-resistant bacteria. Artif Cells Nanomed Biotechnol 46:S399-S413

Amini A, Namvar AE (2019) Antimicrobial resistance pattern and presence of beta-lactamase genes in Pseudomonas aeruginosa strains isolated from hospitalized patients, Babol-Iran. J Med Bacteriol 8:6

Azam A, Ahmed AS, Oves M, Khan MS, Habib SS, Memic A (2012) Antimicrobial activity of metal oxide nanoparticles against Gram-positive and Gramnegative bacteria: a comparative study. Int J Nanomedicine 7:6003-6009

Aziz Zahid S, Albukhaty S, Abbood HK (2017) Prevalence and antibiotic resistance pattern of certain types of bacterial flora in uterine ewe's samples. Karbala Int J Mod Sci 3:259-266

Bahari S, Zeighami H, Mirshahabi H, Roudashti Sh, Haghi F (2017) Inhibition of Pseudomonas aeruginosa quorum sensing by subinhibitory concentrations of curcumin with gentamicin and azithromycin. J Glob Antimicrob Resist 10:21-28

Bortolotti D, Claudio T, Alessandra B, Paolo M, Vinicio Z, Andrea A, Valentina G, Carlo C, Giuseppe V, Mariangela S, Giulia T, Anna F, Dario DL, Roberta R (2019) Conjugation of LasR quorum-sensing inhibitors with ciprofloxacin decreases the antibiotic tolerance of $P$. aeruginosa clinical strains. J Chem 2019:13

Cuprys A, Pulicharla R, Lecka J, Brar SK, Drogui P, Surampalli RY (2018) Ciprofloxacin-metal complexes-stability and toxicity tests in the presence of humic substances. Chemosphere 202:549-559

Curutiu C, lordache F, Lazar V, Magdalena PA, Pop A, Carmen Chifiriuc M, Maria Hoban A (2018) Impact of Pseudomonas aeruginosa quorum sensing signaling molecules on adhesion and inflammatory markers in endothelial cells. Beilstein J Org Chem 14:2580-2588

Driscoll JA, Brody SL, Kollef MH (2007) The epidemiology, pathogenesis and treatment of Pseudomonas aeruginosa infections. Drugs 67:351-368

El-Mowafy SA, Abd El Galil KH, El-Messery SM, Shaaban MI (2014) Aspirin is an efficient inhibitor of quorum sensing, virulence and toxins in Pseudomonas aeruginosa. Microb Pathog 74:25-32

El-Shaer S, Shaaban M, Barwa R, Hassan R (2016) Control of quorum sensing and virulence factors of Pseudomonas aeruginosa using phenylalanine arginyl beta-naphthylamide. J Med Microbiol 65:1194-1204

Gopu V, Meena CK, Shetty PH (2015) Quercetin influences quorum sensing in food borne bacteria: in vitro and in silico evidence. PLOS ONE 10(8):e0134684

Gupta P, Chhibber S, Harjai K (2016) Subinhibitory concentration of ciprofloxacin targets quorum sensing system of Pseudomonas aeruginosa causing inhibition of biofilm formation and reduction of virulence. Indian J Med Res 143:643-651 
He X, Hwang HM, Aker WG, Wang P, Lin Y, Jiang X, He X (2014) Synergistic combination of marine oligosaccharides and azithromycin against $P$ seudomonas aeruginosa. Microbiol Res 169:759-767

Heidari A, Noshiranzadeh N, Haghi F, Bikas R (2017) Inhibition of quorum sensing related virulence factors of Pseudomonas aeruginosa by pyridoxal lactohydrazone. Microb Pathog 112:103-110

Hentzer M, Wu H, Andersen JB, Riedel K, Rasmussen TB, Bagge N, Kumar N, Schembri MA, Song Z, Kristoffersen P, Manefield M, Costerton JW, Molin S, Eberl L, Steinberg P, Kjelleberg S, Hoiby N, Givskov M (2003) Attenuation of Pseudomonas aeruginosa virulence by quorum sensing inhibitors. EMBO J 22(15):3803-3815

Hoffmann N, Lee B, Hentzer M, Rasmussen TB, Song Z, Johansen HK, Givskov M, Høiby N (2007) Azithromycin blocks quorum sensing and alginate polymer formation and increases the sensitivity to serum and stationarygrowth-phase killing of Pseudomonas aeruginosa and attenuates chronic $P$. aeruginosa lung infection in $\mathrm{Cftr}^{-/-}$mice. Antimicrob Agents Chemother 51:3677-3687

Khan M, Ali M, Juyal D (2017) Ciprofloxacin metal complexes and their biological activities: a review. Pharma Innov 6(5):73-78

Klrissa S, Katouli M (2016) Pseudomonas aeruginosa: a review of their pathogenesis and prevalence in clinical settings and the environment. Infect Epidemiol Med 2:8

Lee J, Zhang $L$ (2015) The hierarchy quorum sensing network in Pseudomonas aeruginosa. Protein Cell 6:26-41

Manner S, Fallarero A (2018) Screening of natural product derivatives identifies two structurally related flavonoids as potent quorum sensing inhibitors against Gram-negative bacteria. Int J Mol Sci 19(5)

Packiavathy IASV, Agilandeswari P, Syed Musthafa K, Pandian S, Veera Ravi A (2012) Antibiofilm and quorum sensing inhibitory potential of Cuminum cyminum and its secondary metabolite methyl eugenol against Gram negative bacterial pathogens. Food Res Int 45:85-92
Roudashti S, Zeighami H, Mirshahabi H, Bahari S, Soltani A, Haghi F (2017) Synergistic activity of sub-inhibitory concentrations of curcumin with ceftazidime and ciprofloxacin against Pseudomonas aeruginosa quorum sensing related genes and virulence traits. World J Microbiol Biotechnol 33(3):50

Sabale PM, Kaur P, Patel Y, Patel J, Patel R (2012) Metalloantibiotics in therapy: an overview. J Chem Pharm Res 4:4921-4936

Sadeek SA, El-Attar MS, Abd El-Hamid SM (2015) Synthesis and characterization and antibacterial activity of some new transition metal complexes with ciprofloxacin-imine. Bull Chem Soc Ethiop 29:15

Sheldrick GM (2015) Crystal structure refinement with SHELXL. Acta Cryst C71:3-8

Software, CrysAlisPro in Xcalibur R (2015) CrysAlisPro in Xcalibur R Software, Rigaku Oxford-Diffraction. In.: Poland

Starkey M, Lepine F, Maura D, Bandyopadhaya A, Lesic B, He J, Kitao T, Righi V, Milot S, Tzika A, Rahme A (2014) Identification of anti-virulence compounds that disrupt quorum-sensing regulated acute and persistent pathogenicity. PLoS Pathog 10(8):e1004321

Tang K, Zhang XH (2014) Quorum quenching agents: resources for antivirulence therapy. Mar Drugs 12(6):3245-3282

Tewes F, Bahamondez-Canas TF, Smyth HDC (2019) Efficacy of ciprofloxacin and its copper complex against Pseudomonas aeruginosa biofilms. AAPS PharmSciTech 20(5):205

Uivarosi V (2013) Metal complexes of quinolone antibiotics and their applications: an update. Molecules 18(9):11153-11197

\section{Publisher's Note}

Springer Nature remains neutral with regard to jurisdictional claims in published maps and institutional affiliations.

\section{Submit your manuscript to a SpringerOpen ${ }^{\odot}$ journal and benefit from:}

- Convenient online submission

- Rigorous peer review

- Open access: articles freely available online

- High visibility within the field

- Retaining the copyright to your article

Submit your next manuscript at $\boldsymbol{\nabla}$ springeropen.com 